\title{
THE COSTS OF MEDICAL CARE FOR COVID-19 PATIENTS: A CASE STUDY IN TURKEY
}

\author{
Cenk Tekerl, Dogancan Cavmak*2, Hakan Avci3 \\ 1. Vocational School, Nisantasi University, Turkey \\ 2. Vocational School of Healthcare Services, Tarsus University, Turkey \\ 3. Healthcare Management Programme, Nisantasi University, Turkey
}

Correspondence: dogancavmak@tarsus.edu.tr

\section{ABSTRACT}

\section{OBJECTIVE:}

This study aims to calculate the medical costs of Covid-19 patients for hospitals based on the severity of clinical care.

\section{DESIGN:}

The study was conducted in a hospital in Istanbul/Turkey. A micro-costing approach was performed using historical cost data for one year. All direct and indirect medical inputs were determined in quantities and monetary values for four types of Covid-19 patients in the hospital.

\section{RESULTS:}

The analysis calculated the unit cost of an outpatient to be 459,99 $€$, while the cost per day for inpatient to be 1.184,63 for non-intubated in intensive care unit to be 1.938,11, for intubated in the intensive unit to be 2.393,99も. The study also indicates that the total cost of a non-intubated patient in intensive care units is 1,54 times higher than the total cost per inpatient. An intubated patient's cost is 2,08 times higher than an inpatient's cost.

\section{CONCLUSION:}

This study indicates that Covid-19 patients incur significantly high costs for hospitals. The findings of the study provide empirical data for different types of patients which can be used in clinical management and can help all related governing bodies to plan their actions and make the decisions.

\section{KEYWORDS}

Covid-19, hospitalization, health care costs, Turkey 
Since it has been declared as a pandemic, there have been over 180 million confirmed Covid-19 cases worldwide. [1] Covid-19 can cause severe respiratory disease and long-term hospitalization. Medical care for Covid-19 patients is complex and costly. Especially, the treatment procedure is getting complex as the symptom severity increases. [2] There is evidence that direct medical costs of symptomatic Covid-19 cases are higher than other infectious diseases. [3] Due to the high number of cases and its complexity, the pandemic put many countries and hospitals' capacity to a severe level. Hospitals in the regions with great numbers of Covid-19 cases had to operate over capacity most of the time. [4] Many hospitals have been affected by the burden of Covid-19 patients. The pandemic has negative impacts on hospitals' revenue cycle, financial operations, and service operations. [5] According to early reports, Covid-19 hospitalizations caused nearly $\$ 36.6$ billion loses from March to June 2020 in the United States. Hospitals have been also suffering from additional costs caused by Covid-19 treatment such as personal protective equipment (PPE) and costs of front-line workers. American Hospital Association indicated that nontreatment costs for hospitals were $\$ 2.4$ billion for a period of 4 months. [6]

Turkey has over 5 million confirmed cases so far. Nearly 50.000 people have died due to Covid-19. Ministry of Health reported that the hospitalization rate was \%53,1 among all Covid 19 patients while $\% 7,8$ of them were intubated by the date August 2020. [7] According to the study carried out by Istanbul University Cerrahpasa Medical Faculty and Baskent University, direct medical costs of Covid-19 constituted \%2 of total public healthcare expenditure. The burden of the pandemic on the health system for 12 months was calculated as 3.7 billion Turkish Lira. The study also indicated that costs were nearly duplicated for patients with severe symptoms especially those in intensive care units. [8]

All the hospital managers around the world experienced how much a communicable disease can affect their managerial process during the last year. [9] Hospitals need to analyze costs to ensure financial sustainability. This is much more important in pandemic conditions which cause a decrease in hospitals' revenue while an increase in costs Unit costs calculation may be useful in budgeting and allocation resources for Covid-19 medical treatment with 
costs of a new treatment method and includes procedure variations. A micro-costing approach enables researchers to go deeper into the case and analyze all the inputs related to medical care and patients. [18] Considering the aim to shed light on resource consumption and medical costs of different types of Covid-19 patients, micro-costing stands out as the most appropriate method. There are many studies on the cost of different diseases $[19,20]$ including Covid-19 [11] which have used a micro-costing approach.

The study was conducted in a private hospital in Istanbul. The historical costs were used for calculations. The data were obtained for 1 year (04.2020-04.2021) The costing process was carried out in three phases. At all phases, faceto-face conversations were carried out with the hospital manager, physicians, clinical managers, and head of accounting departments. A template that includes input variables for each type of patient was designed on Excel software to collect cost data. In the first phase, the types of Covid-19 patients in the hospital were determined. The cost calculation was made for four types: outpatients, inpatients, intubated patients in ICU, and non-intubated patients in ICU. Secondly, relevant inputs that are consumed to provide medical care for each patient type were identified. Thirdly, quantities and monetary values of inputs were calculated. In the identification process of inputs and their quantities, conversations were carried out by physicians and clinical managers. For each type of patient, required inputs including labor force were determined. The time spent by the physician for each type was determined by observing and using a timer. For each type of patient, costs of staff, laboratory and radiology costs, pharmaceuticals costs and costs of medical consumables, personal protective equipment, cost of oxygen, and cost of accommodation were calculated based on the data on quantities and theirs' monetary values.

\section{TYPES OF PATIENTS AND UNITS}

Outpatients refer to those who test positive for Covid-19 but do not need medical care in the hospital. They are asymptomatic or mild symptomatic on home-based care. They are given medicine which is provided and compensated by the Social Security Institution and isolated in their own home. Inpatients refer to those who are moderately symptomatic. They are admitted to the hospital for isolated general wards and may need oxygen support. Intubated patients are patients with severe symptoms admitted to intensive care units (ICU). They are under invasive mechanical ventilation. Non-intubated patients are also with severe symptoms but breathing stable just provided oxygen support if it is needed. For the outpatients, the costs were calculated per patient. For inpatients and patients with severe symptoms, the unit is per day (total cost per day- TCPD). We calculated the total cost per patient (TCPP) for inpatients and ICU multiplying the cost per day by the average length of stay.

\section{MEASURING INPUTS}

Direct and indirect costs of medical care for Covid-19 were considered separately for four types of patients. All inputs were determined using patient information documents and records of clinical departments. Medical care procedures were observed and examined in outpatient and inpatient departments and intensive care units. These procedures mostly follow the Covid-19 Patient Treatment regulations published by the Turkish Ministry of Health [21]. Considering the treatment procedure, the cost categories of the study are determined as; direct and indirect labor, medical consumables, Covid-19 test kits, laboratory tests, costs of radiological examinations, and accommodation (Table 1).

TABLE 1. COST CATEGORIES FOR COVID-19 PATIENTS.

\begin{tabular}{|l|l|}
\hline Cost Category & Inputs \\
\hline Staffing/Labor & $\begin{array}{l}\text { Medical doctors, nurses, anesthetists, medical } \\
\text { secretaries }\end{array}$ \\
\hline Medical consumables and pharmacies & $\begin{array}{l}\text { PPEs, endotracheal tubes, nasal cannula, } \\
\text { catheters, hygiene and disinfectants } \\
\text { Paracetamol, Azithromycin, Dexamethason, } \\
\text { Propofol, Morphine }\end{array}$ \\
\hline
\end{tabular}




\begin{tabular}{|l|l|}
\hline Laboratory & $\begin{array}{l}\text { Costs of labor, amortization and consumables } \\
\text { aggregated to calculate per CRP, hemogram, } \\
\text { D-dimers, blood gas analysis. }\end{array}$ \\
\hline Radiological examination & $\begin{array}{l}\text { Costs of labor, amortization and consumables } \\
\text { aggregated to determine cost of a CT scan }\end{array}$ \\
\hline Oxygen support & $\begin{array}{l}\text { Oxygen consumption based on users' } \\
\text { information }\end{array}$ \\
\hline Accommodation & $\begin{array}{l}\text { Patient bed and bed linen, patient monitors, } \\
\text { mechanical ventilator, cleaning, laundry, } \\
\text { electricity and catering. }\end{array}$ \\
\hline
\end{tabular}

\section{Labor/staffing}

The data for staffing was obtained on the type of staff which are medical doctors, nurses, medical technicians, and medical secretaries. The direct labor costs consisted of doctors and nurses while indirect costs are the costs of medical secretaries. Technicians refer to laboratory and radiology departments' staff. The costs of technicians were included in the department which they work for and were used to calculate radiological and laboratory costs. Labor costs are calculated by using the data of the human resources department. Staff providing clinical care for inpatients and patients in ICU are medical doctors, anesthetists and nurses. To allocate direct labor cost time spent on a patient in a day determined. Indirect labor costs for patients include the costs of medical secretaries which are allocated using the ratio of total cost divided by the number of patients. Firstly, for inpatients and ICU patients, the total medical staff time in hours and the cost of an hour were calculated. Costs include day and night shifts. Secondly, the time spent by each staff for each type of patient was determined on average based on the information obtained from doctors, nurses and department managers. For example, patients in ICU get 4 visits from medical doctors in a day that makes 4 hours of direct clinical care in a day. Finally, the time allocated for patients and cost for an hour were multiplied to have the labor cost for each patient type (For instance 4 hours * 59, 84=239, 39も). For outpatients, the total costs of doctors are divided by the number of patients.

\section{Pharmaceuticals and medical consumables}

Consumables stand for non-durable items which can be used at most for a year effectively. It includes personal protective equipment (PPE), disinfectant, and hygiene material in the case of Covid-19 patients. PPE includes medical gloves, medical coveralls, visors and N95 masks. The amount of consumption was determined based on users' information. For example, it was determined that 4 pairs (1 for doctor, 1 for laboratory, 1 for radiology, 1 for PCR test) of gloves were used for one outpatient. For clinical care in a day approximately, 2 N95 masks, 1 gogle, 5 latex gloves, 4 shoe covers, etc. are being used by staff. The costs of coveralls are mostly incurred in inpatient and ICU. Medical consumables also include disposable medical equipment; endotracheal tubes, nasal cannula, catheters which are used for ICU patients once during the care.

The costs of medicines (pharmaceuticals) are included in medical consumables in reported tables (direct cost). Consumed medicines by different types of patients were determined in types and quantities based on information obtained from medical doctors and nurses in charge and Covid-19 Patient Treatment regulations published by the Turkish Ministry of Health. [21] Inpatients in the general ward typically 1 gram paracetamol three times, $500 \mathrm{mg}$ azithromycin, and $6 \mathrm{mg}$ dexamethasone once in a day. Intubated patients additionally get propofol for intubation and morphine for sedation and parenteral feeds. Propofol is given $1 \mathrm{mg}$ per kilogram and morphine $10 \mathrm{mg}$ every 4 hours according to doctor orders. The costs of each medical consumable are calculated using purchasing prices obtained from accounting records.

\section{Laboratory and radiological examinations}

The total costs of the departments were calculated including direct costs and overheads. Then, unit costs were calculated by dividing total costs by the number of tests. In radiology, the cost of a CT scan was calculated. Outpatients take $1 \mathrm{CT}$ scan, inpatients in general wards and ICU take 2, and intubated patients take 3 CT scans. In the laboratory, the costs of a CRP, a hemogram, and D-dimer 
tests which are examined for Covid-19 patients were calculated. Unit costs were transferred by the number of tests performed for the patients. For instance, CRP, full hemogram and D-dimers are carried out for once for outpatients after PCR test. Costs of on CRP, hemogram, and D-dimer make 60t. Another CRP and hemogram test are carried out for inpatients during care episodes which bring an additional cost of 20 .

\section{Oxygen support}

Nearly half of patients in general wards receive oxygen support 2L/min. Non-intubated patients get 10L/min, while patients with critical disease in ICU $15 \mathrm{~L} / \mathrm{min}$. The costs of oxygen was determined on average calculations due to difficulty in measuring exact flow. The cost of oxygen per patient in general ward was assumed to be 100 , while it is 225 for a non-intubated and 300 for an intubated patient.

\section{Accommodation}

The per-day costs for accommodation were obtained. The costs of accommodation include the cost of the bed, cleaning, laundry, electricity, and catering. The amortization costs of medical equipment such as patient monitors, mechanical ventilators, beds are also included in this section. This cost is valid for inpatient and ICU patients. The cost of a day for accommodation was calculated using data for mentioned components. The average length of stay was used for allocating costs to patients.

\section{RESULTS}

Table 2. outlines the number of patients and length of stay for a year for each type. The total number of Covid-19 patients for a year was 6.242. 20,34 \% of patients were inpatients while $14,65 \%$ were ICU patients. The highest average length of stay belongs to patients who intubated in ICU.

Table 3 outlines the cost of an outpatient who is asymptomatic or mild symptomatic. This type gets no medical care in the hospital. The costs of these patients mostly consist of labor and radiological costs. The cost of an outpatient is estimated to be 459,99も. A standard Covid19 outpatient gets a CT scan after laboratory tests and first PCR and then needs to test negative out of three examinations to be released from home quarantine. Therefore, the PCR costs include the costs of three examinations. Laboratory costs refer to CRP, hemogram and D-dimer examinations before the diagnose. According to results, outpatients mostly incur costs related to PCR test $(42,39 \%)$ and radiological examination $(26,90 \%)$.

TABLE 2. THE NUMBER OF PATIENTS AND LENGTH OF STAY BY PATIENT TYPES.

\begin{tabular}{|l|l|l|l|}
\hline Types & Number of patients & $\begin{array}{l}\text { Total length of stay } \\
\text { (day) }\end{array}$ & $\begin{array}{l}\text { Average length of } \\
\text { stay }\end{array}$ \\
\hline Outpatients & 4057 & - & - \\
\hline Inpatients & 1270 & 10.703 & 8,43 \\
\hline ICU-intubated & 657 & 5.710 & 8,70 \\
\hline ICU-non-intubated & 258 & 2059 & 7,98 \\
\hline
\end{tabular}

TABLE 3. COSTS OF COVID-19 OUTPATIENTS

\begin{tabular}{|l|l|l|l|}
\hline \multicolumn{2}{|l|}{ Inputs } & Turkish Lira $t$ & $\begin{array}{l}\text { \% of total cost } \\
\text { per patient }\end{array}$ \\
\hline Labor costs & Direct & 53,33 & $11,59 \%$ \\
\cline { 2 - 4 } & Indirect & 18,94 & $4,12 \%$ \\
\hline Medical consumables & Indirect & 9,72 & $2,11 \%$ \\
\hline Covid-19 test (PCR) & & $42,39 \%$ \\
\hline Laboratory tests & 195 & $13,04 \%$ \\
\hline Radiological examination (CT) & 60 & $26,09 \%$ \\
\hline TCPP & 120 & $100 \%$ \\
\hline $\begin{array}{l}\text { Total outpatient cost (TCPP } \times \text { number of patients for } \\
\text { a year }\end{array}$ & $1.866 .179,43$ & \\
\hline
\end{tabular}


Table 4 outlines the costs of an inpatient who is in general hospital wards. Per-day unit cost for an inpatient is estimated to be $1.184,63$. This makes a 9.986,431 total cost per patient. Inpatients incur higher labor and medical consumables costs. These patients also get oxygen support and incur an accommodation cost. The medical care time spent of inpatient is higher than an outpatient by nearly $\% 55$. Total cost of an inpatient in general wards consists of $\% 13,16$ labor cost, \%10,60 medical consumable costs, \%16,46 PCR cost, \%20,26 CT scan cost and \%25,32 accommodation cost. The cost of a mild symptomatic inpatient differs from outpatient in terms of accommodation and basic oxygen support. When an outpatient just gets an ordinary examination by the physician, an inpatient gets two visits in a day. An inpatient also consumes medicines and some direct medical consumables. They get at least two CT scans. Therewithal, accommodation costs which include laundry and catering incur for an inpatient.

Table 5 and 6 outlines costs for patients in ICU. The costs of ICU patients differ from inpatients because of additional costs especially for labor, medical consumables, oxygen, and accommodation. The largest share of costs for ICU patients is accommodation $(\% 30,96)$. Severe patients also incur higher labor costs $(\% 16,53)$ due to more staff are being involved and more time spent per patient. The costs of medical consumables $(\% 10,2)$ are higher because of pharmaceuticals (direct cost) and PPE (indirect). \% 11,61 of the total cost is oxygen for non-intubated patients in ICU.

Intubated patients incur higher medical consumables cost and oxygen costs than non-intubated ones. Pharmaceuticals are important contributors to medical consumables costs. \%11,76 of the total cost is the cost of medical consumables. The biggest share is taken by accommodation with \%25,06. Additionally, costs of laboratory tests $(\% 10,86)$ and costs of radiological examination $(\% 15,04)$ are higher for intubated patients. The average length of stay for intubated patients $(8,70)$ is longer than non-intubated ones $(7,98)$. While a relatively small difference occurs in per day cost, due to longer length of stay, total cost per intubated patient is dramatically higher compared to non-intubated patients.

TABLE 4. COSTS OF COVID-19 INPATIENTS

\begin{tabular}{|l|l|l|l|}
\hline \multicolumn{2}{|l|}{ Inputs } & Turkish Lira $\mathbf{t}$ & $\begin{array}{l}\text { \% of total cost } \\
\text { per day }\end{array}$ \\
\hline \multirow{2}{*}{ Labor costs } & Direct & 117,96 & $9,96 \%$ \\
\cline { 2 - 4 } & Indirect & 37,89 & $3,20 \%$ \\
\hline $\begin{array}{l}\text { Medical } \\
\text { consumables }\end{array}$ & Direct & 75,6 & $6,38 \%$ \\
\cline { 2 - 4 } & Indirect & 38,18 & $3,22 \%$ \\
\hline Covid-19 test (PCR) & 195 & $16,46 \%$ \\
\hline Oxygen & 100 & $8,44 \%$ \\
\hline Laboratory tests & 80 & $6,75 \%$ \\
\hline Radiological examination (CT) & 240 & $20,26 \%$ \\
\hline Accommodation & 300 & $25,32 \%$ \\
\hline TCPD & $1.184,63$ & $100 \%$ \\
\hline TCPP (TCPD x average length of stay) & $9.986,431$ & \\
\hline $\begin{array}{l}\text { Total inpatient cost (TCPP } x \text { number of patients for } \\
\text { a year) }\end{array}$ & $12.682 .767,243$ & \\
\hline
\end{tabular}


TABLE 5. COSTS OF COVID-19 NON-INTUBATED PATIENTS IN ICU

\begin{tabular}{|c|c|c|c|}
\hline \multicolumn{2}{|l|}{ Inputs } & Turkish Lira $€$ & $\begin{array}{l}\% \text { of total cost per } \\
\text { patient }\end{array}$ \\
\hline \multirow[t]{2}{*}{ Labor costs } & Direct & 239,39 & $12,35 \%$ \\
\hline & Indirect & 81,06 & $4,18 \%$ \\
\hline \multirow{2}{*}{$\begin{array}{l}\text { Medical } \\
\text { consumables }\end{array}$} & Direct & 151,2 & $7,80 \%$ \\
\hline & Indirect & 46,46 & $2,40 \%$ \\
\hline \multicolumn{2}{|c|}{ Covid-19 test (PCR) } & 195 & $10,06 \%$ \\
\hline \multicolumn{2}{|l|}{ Oxygen } & 225 & $11,61 \%$ \\
\hline \multicolumn{2}{|c|}{ Laboratory tests } & 160 & $8,26 \%$ \\
\hline \multicolumn{2}{|c|}{ Radiological examination (CT) } & 240 & $12,38 \%$ \\
\hline \multicolumn{2}{|c|}{ Accommodation. } & 600 & $30,96 \%$ \\
\hline \multicolumn{2}{|l|}{ TCPD } & $1.938,11$ & $100 \%$ \\
\hline \multicolumn{2}{|c|}{ TCPP (TCPD $x$ average length of stay) } & \multicolumn{2}{|l|}{$15.466,1178$} \\
\hline \multicolumn{2}{|c|}{$\begin{array}{l}\text { Total intubated patients cost (TCPP x number of } \\
\text { patients for a year) }\end{array}$} & \multicolumn{2}{|l|}{$3.990 .258,39$} \\
\hline
\end{tabular}

TABLE 6. COSTS OF COVID-19 INTUBATED PATIENTS IN ICU

\begin{tabular}{|l|l|l|l|}
\hline \multicolumn{2}{|l|}{ Inputs } & Turkish Lira $\neq$ & $\begin{array}{l}\text { \% of total cost per } \\
\text { patient }\end{array}$ \\
\hline \multirow{2}{*}{ Labor costs } & Direct & 239,39 & $10,00 \%$ \\
\cline { 2 - 4 } & Indirect & 81,06 & $3,39 \%$ \\
\hline $\begin{array}{l}\text { Medical } \\
\text { consumables }\end{array}$ & Direct & 226,8 & $9,47 \%$ \\
\cline { 2 - 4 } & Indirect & 54,74 & $2,29 \%$ \\
\hline Oxygen & 195 & $8,15 \%$ \\
\hline Laboratory tests & 300 & $12,53 \%$ \\
\hline Radiological examination (CT) & 260 & $10,86 \%$ \\
\hline Mechanic ventilation & 360 & $15,04 \%$ \\
\hline Accommodation. & 77 & $3,22 \%$ \\
\hline TCPD & 600 & $25,06 \%$ \\
\hline TCPP (TCPD x average length of stay) & $2.393,99$ & $100 \%$ \\
\hline $\begin{array}{l}\text { Total not-intubated patients cost (TCPP x number } \\
\text { of patients for a year) }\end{array}$ & $13.683 .805,47$ & \\
\hline
\end{tabular}


Graph 1 indicates the costs difference between patient times higher than an inpatients cost. An intubated patient's types. The total cost per inpatient is 21,71 times higher than cost is 2,08 times higher than total cost per inpatient.

an outpatient. The total cost of non-intubated in ICU is 1,54

GRAPH 1. COST OF COVID-19 PER PATIENT FOR EACH TYPE OF PATIENTS

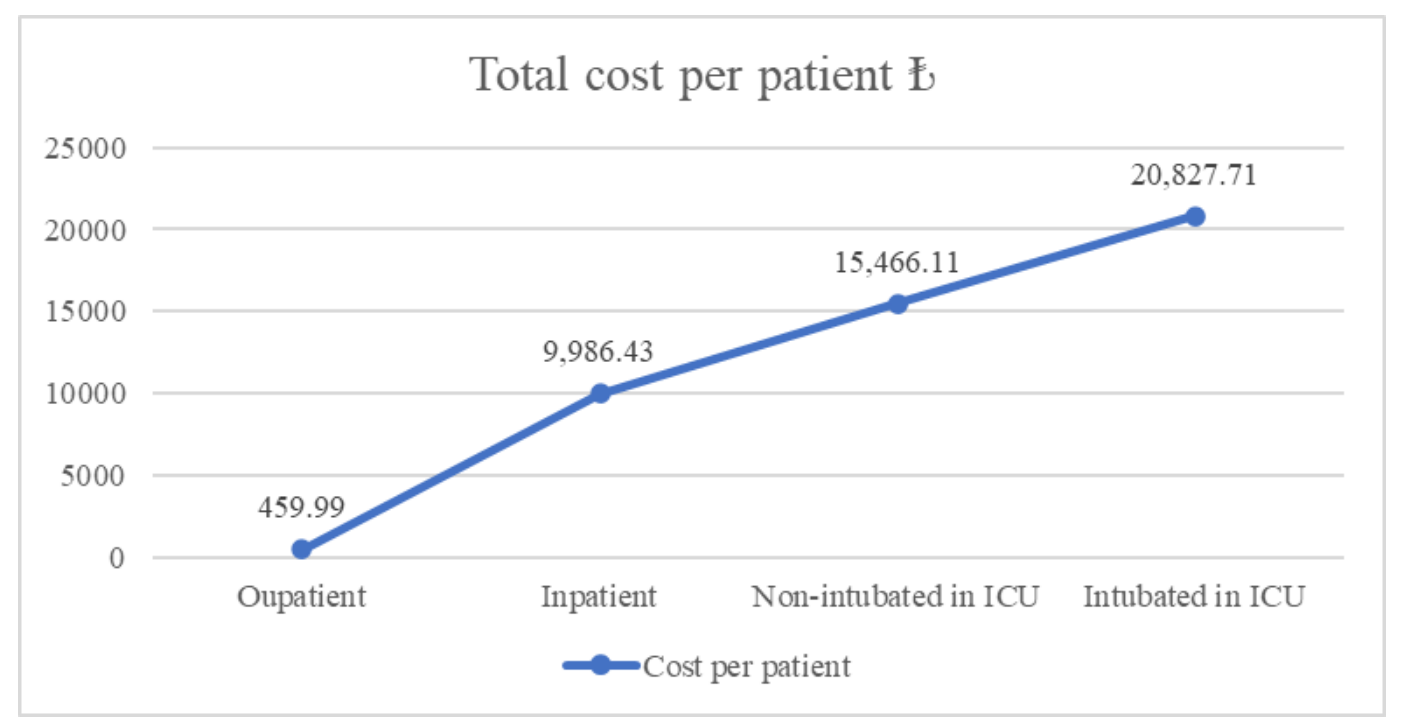

\section{DISCUSSION}

The Covid-19 pandemic causes significant challenges to hospitals in terms of resource consumption and cost management. Governments and hospitals have to make difficult decisions on resource allocation. Empirical data is substantial for decision-making. Deci-sion-makers could benefit from cost studies on Covid-19 medical care to be able to make decisions precisely. This study provides a deeper understanding of medical care processes and resource consumption. To the best of our knowledge, there is a limited number of studies on the medical costs of Covid-19. Although these studies provide significant findings for further studies and decision makers, a few provide empirical data. In a study that calculated unit costs for asymptomatic patients and patients with mild-tomoderate COVID-19 disease under home-based care were in Kenya, it has been found that COVID-19 case management costs are substantial for all treatment categories and in-crease as severity increases. [13] A study that considered only direct medical costs of Covid-19 in South Africa indicated that the highest average daily cost was for ICU admissions. [11] A study in Saudi Arabia also outlines those admissions to general medical wards incur fewer costs than admission to the ICU. [22]

In the current study, an estimation for four types of patients has been conducted using a micro-costing approach in a private hospital. The study provides empirical evidence on the costs of Covid-19 patients' medical care processes. Unit costs for the different types of asymptomatic, moderately and severely symptomatic patients are presented. Given that the severity of clinical indicators varies by patient type, different types and quantities of inputs are used for clinical care. As much as possible inputs which are related to medical care for patients are provided in monetary values based on available data. The results show that cost of medical treatment increase as severity increases. The highest medical cost per patient was estimated for ICU patients. The cost of a day for an intubated patient was 2.393,99 when the average length of stay was 8,70 . That makes a total of $20.827,71$ cost per patient in ICU. This amount is 2,08 times higher than the cost per inpatient and 45,27 times higher than the cost per outpatient. The costs of accommodation and medical consumables especially come to the front for ICU patients. This means the cost of Covid-19 is mostly incurred from hospitalization.

The cost of medical care for Covid-19 is not an important topic only for hospitals. The burden of the cost related to Covid is also affecting the social health insurance system in Turkey. Nearly all expenses are covered by General Health Insurance which is under Social Security Institution regardless of the care is provided in private or public hospitals. As the severity of cases increases, the medical costs are increasing the burden on the health and social security system. Therefore, this type of study can help all 
related governing bodies to plan their activities and to make decisions.

The current study is not without limitations. The study has three main limitations. First, an exact determination for some inputs was not possible due to their unstandardized use. For example, PPE and disinfectant costs and oxygen are mostly determined based on users' information. Second, pharmaceutical consumption was calculated mostly based on information obtain from caregivers. Finally, the study presents findings for the private healthcare sector in Turkey. The costs may differ in public hospitals.

\section{CONCLUSIONS}

In this hospital-based Covid-19 cost calculation study, costs of outpatients and hospitalized patients were examined in a broad framework. The study provides useful insights into the costs of treatment of Covid-19 in Turkey providing detailed information on consumed inputs for the treatment. Following conclusions and recommendations can be drawn from the results of the study;

- Treatment for Covid-19 gets complicated so that requires more medical consumables as the level of care increases. Healthcare providers need to periodically analyze resource consumption to ensure financial sustainability.

- The cost of treatment increases dramatically as the severity of cases increases. This highlights the importance of preventive approaches for Covid-19. It is recommended for hospitals, policy, and decision makers to enhance the preventive public health programs.

- Calculating costs per patient is a hard effort in hospitals due to complex and insufficient data. It is recommended for hospitals to establish an effective cost accounting system in their accounting mechanism to be able to track costs easily.

- The limitations of the study constrict the recommendations to a narrow-scoped implication area. Further studies may benefit from data from this study to conduct more comprehensive studies including public hospitals or health systems as a whole.

\section{References}

1. WHO.int. [Cited 2021 SEPT 5] Available from: https://covid 19.who.int

2. Eisenberg MD, Barry CL, Schilling CL, KennedyHendricks A.. Financial risk for COVID-19-like respiratory hospitalizations in consumer-directed health plans. Am J Prev Med 2020; 59(3): 445-448.

3. Bartsch SM, Ferguson MC, McKinnell JA, O'shea KJ, Wedlock PT, Siegmund SS, Lee BY. The potential health care costs and resource use associated with covid-19 in the United States: a simulation estimate of the direct medical costs and health care resource use associated with covid-19 infections in the United States. Health Aff 2020; 39(6): 927-935.

4. Glied S, Levy H. The potential effects of coronavirus on national health expenditures. Jama 2020; 323(20): 2001-2002.

5. Raghuvanshi VP, Raghuvanshi SP. Implications and future strategies on cost management for hospitals during and after COVID-19. Int J Community Med Public Health 2020; 7(6): 2405.

6. American Hospital Association. int. [Cited 2020] Hospitals and Health Systems Face Unprecedented Financial Pressures Due to COVID-19. Available from: https://www.aha.org/system/files/media/file/2020/05/ aha-covid19-financial-impact-0520-FINAL.pdf

7. Ministry of Health. [Cited 2021] Covid-19 Weekly Situation Report 17/08-23/08/2020. Available from: https://covid19.saglik.gov.tr/Eklenti/38906/0/covid-19weekly-situation-report---34weekpdf.pdf? $\operatorname{tag} 1=$ CCCCBBB6DED7755220C08077A 8DF4F7D49B93E7A

8. Anadolu Agency (AA) [Cited 2021] Available from: https://www.aa.com.tr/tr/sirkethaberleri/saglik/kovid19-un-turkiye-saglik-ekonomisine-yuku-3-7-milyar-lirayiasti/663386 :

9. Malhan S, Torgay A, Kavuncubası S, Alzhanov S, Kikimbayeva R, Malchenko V, Haberal A. What we Learned from Covid19 on behalf of Hospital Management?. Glob J Med Clin Mini Reviews 2020; 7(2): 107-108.

10. Bartsch SM, Ferguson MC, McKinnell JA, et al. The potential health care costs and resource use associated with COVID-19 in the United States. Health Aff (Millwood). 2020;39:927-35 
11. Edoka I, Fraser H, Jamieson L, Meyer-Rath G, Mdewa W. Inpatient care costs of COVID-19 in South Africa's public healthcare system. Int. J. Health Policy Manag. $2021 ; x(x): 1-8$

12. Ohsfeldt, R. L., Choong, C. K. C., Mc Collam, P. L., Abedtash, H., Kelton, K. A., Burge, R.. Inpatient Hospital Costs for COVID-19 Patients in the United States. Advances in therapy $2021 ; 38(11), 5557-5595$.

13. Barasa E, Kairu A, Maritim M, Were V, Akech S, Mwangangi $M$. Examining unit costs for COVID-19 case management in Kenya. BMJ Glob. Health 2021; 6(4): e004159.

14. Thant, P. W., Htet, K. T., Win, W. Y., Htwe, Y. M., Htoo, T. S. Cost Estimates of COVID-19 Clinical Management in Myanmar. BMC Health Services Research Pre Print, 2021.

15. Tsai, Y., Vogt, T. M., Zhou, F.. Patient characteristics and costs associated with COVID-19-related medical care among Medicare fee-for-service beneficiaries. Annals of Internal Medicine 2021.

16. Di Fusco, Manuela, et al. Health outcomes and economic burden of hospitalized COVID-19 patients in the United States. Journal of Medical Economics 2021; 308-317.

17. Bai, G., Zare, H. Hospital cost structure and the implications on cost management during COVID-19. Journal of general internal medicine 2020; 35(9), 28072809.

18. Frick, K. D. Micro-costing quantity data collection methods. Medical care 2009; 47(7 Suppl 1), 76-81.

19. Ruof, J., Hülsemann, J. L., Mittendorf, T., Handelmann S., Von Der Schulenburg, J. M., Zeidler, H., Merkesdal, S. Costs of rheumatoid arthritis in Germany: a microcosting approach based on healthcare payer's data sources. Annals of the rheumatic diseases 2003; 62(6), 544-549.

20. Lefrant, J. Y., Garrigues, B., Pribil, C., Bardoulat, I., Courtial, F., Maurel, F., CRREA Study Group.. The daily cost of ICU patients: a micro-costing study in 23 French intensive care units. Anaesthesia Critical Care \& Pain Medicine 2015; 34(3), 151-157.

21. T.C. Sağlık Bakanlığı. Covid-19 Erişkin Hasta Tedavisi. Bilimsel Danışma Kurulu Çalışması, 2021.
22. Khan AA, AlRuthia $Y$, Balkhi B, Alghadeer SM, Temsah $\mathrm{MH}$, Althunayyan SM, Alsofayan YM. Survival and estimation of direct medical costs of hospitalized COVID-19 patients in the Kingdom of Saudi Arabia. Int J Environ Res Public Health 2020; 17(20): 7458. 